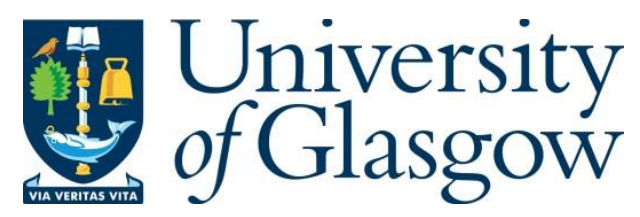

Tan, C., Chen, Q., Zhou, K. and Zhang, L. (2019) A simple high-performance current control strategy for V2G three-phase four-leg inverter with LCL filter. IEEE Transactions on Transportation Electrification, (doi:10.1109/TTE.2019.2936684).

There may be differences between this version and the published version. You are advised to consult the publisher's version if you wish to cite from it.

http://eprints.gla.ac.uk/177269/

Deposited on: 19 August 2019

Enlighten - Research publications by members of the University of Glasgow http://eprints.gla.ac.uk 


\title{
A Simple High-Performance Current Control Strategy for V2G Three-phase Four-leg Inverter with LCL Filter
}

\author{
Cuilan Tan, Qihong Chen, Member, IEEE, Keliang Zhou, Senior Member, IEEE, Liyan Zhang, Member, IEEE
}

\begin{abstract}
Electric vehicles (EVs) can behave as distributed energy storage devices for providing on-demand smart grid support service, that is an emerging Vehicle-to-Grid (V2G) technology. A high-performance and easy-implementation current control strategy for V2G Three-phase four-leg inverter with LCL filter is proposed. It consists of a deadbeat (DB) controller and a paralleled repetitive controller (RC). The DB controller is based on weighted average inductor current (WAIC) scheme, which simplifies the third-order LCL filter to be an equivalent 1st order $L$ filter. The stability of the DB controlled inverter with the unmodelled system time delay is analyzed. DB controller is of very fast response and easy implementation, but is not immune to system time delay and various uncertainties. To overcome the disadvantages, a plug-in $\mathrm{RC}$ is added to reinforce the DB controller to remove harmonic distortion from the feed-in current in the presence of parameter uncertainties. A lab prototype of $10 \mathrm{~kW}$ grid-connected threephase four-leg inverter has been built up to validate the proposed current control strategy. The simulations and experiments are provided to demonstrate the validity of the proposed control strategy.
\end{abstract}

Index Terms-V2G, weighted average inductor current, three-phase four-leg inverter, deadbeat control, repetitive control, stability analysis.

\section{INTRODUCTION}

Vehicle-to-grid (V2G) technology allows electric vehicles (EVs) to act as distributed energy storage devices. It can provide smart grid support services by "valley filling" and "peak shaving" [1-4]. Fig. 1 shows a V2G application example, where the EVs can improve the efficiency, stability and economy of the grid[5, 6].

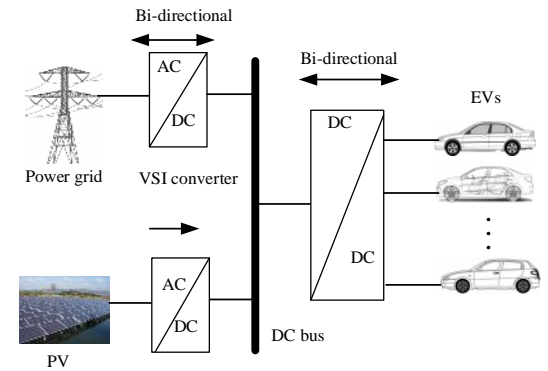

Fig. 1. V2G application system.

This work was partially supported by the National Natural Science Foundation of China under Grant 61673305, 61673306 and the National Key Research and Development Program of China under Grant 2017YFB0103001. (Corresponding author: Liyan Zhang.)

Cuilan Tan is with the Department of School of Automation, Wuhan University of Technology, Wuhan 430070, China, and with School of Physics and Information Engineering, Jianghan University, Wuhan 430056, China (e-mail: xiaotanlan@126.com).
Three-phase four-leg inverters can be employed to interface the EVs with the grid. Compared with conventional three-phase three-wire or three-phase four-wire inverters, the fourth leg allows the neutral point voltage to be actively modified, and then enables the inverter to achieve high utilization of DC bus voltage and feed unbalanced loads, and so on. [7-10]. V2G converters not only are used to charge the EVs from the grid, but also can compensate unbalanced voltages on demand. Hence the four-leg topology is needed in V2G applications at costs of additional switches. It is a must to develop appropriate current control schemes for inverters to fed-in high quality currents in V2G applications. It is well known that the $3^{\text {rd }}$-order LCL filter enable the inverters to achieve much better high frequency current harmonics attenuation than $1^{\text {st }}$ order L filter [11]. However, it might significantly increase the complexity of the analysis and synthesis of the current control methods for inverters[12]. Neglecting the high frequency filtering capacitor $C$, the $3^{\text {rd }}$ order system could be approximated to be a 1st-order system with the sum inductance of two inductors [13]. Hence, a very simple deadbeat (DB) control scheme can be developed for the inverters with the approximated L filter. However, such DB controlled inverters might not be able to feed high-quality current into the grid and has poor damping capability of resonance due to the omission of high frequency response of LCL filter [14]. Instead of ignoring the capacitor C, when a weighted average current value of the two inductors is employed as the feedback in the control loop[15], the $3^{\text {rd }}$ order LCL filter is found to be equivalent to a $1^{\text {st }}$ order L filter [16]. Therefore the weighted average inductor current (WAIC) based DB control scheme can be developed for inverters with LCL filter [17-19]. The WAIC based DB control scheme will significantly simplify the synthesis of the inverter current controller without any system performance and stability degradation. Since the WAIC based DB controller is based on accurate mathematical model, the DB control scheme cannot well remove periodic feed-in current error and harmonics under various uncertainties, also it might encounter instability caused by unmodelled time delay[14, 20].

This paper proposed a WAIC based DB control strategy combined with plug-in repetitive controller (RC) for $\mathrm{V} 2 \mathrm{G}$ three-phase four-leg inverter with LCL filter. The stability of

Qihong Chen is a Professor with School of Automation, Wuhan University of Technology, Wuhan 430070, China (e-mail: chenqh@whut.edu.cn).

Keliang Zhou is a Senior Lecturer with James Watt School of Engineering at the University of Glasgow, Glasgow, G12 8QQ, United Kingdom (e-mail: keliang.zhou@glasgow.ac.uk).

Liyan Zhang is a Professor with School of Automation, Wuhan University of Technology, Wuhan 430070, China (e-mail: zlywhut@whut.edu.cn). 
the DB controlled inverter with the impact of unmodelled system time delay is investigated to facilitate the control synthesis. The WAIC based DB control has fast dynamic response to the reference changes, but it can't track the reference accurately and can't suppress the harmonic effectively. As we know, the internal model principle (IMP) based RC $[21,22]$ can exactly track periodic reference signal or eliminate periodic disturbances. In order to eliminate the residual harmonic distortion and periodic tracking error from the fed-in current in the presence of parameter uncertainties, a plug-in phase-lead compensation RC is added to reinforce the DB controller. The highlights are as following: 1). WAIC based DB control strategy is applied to three-phase four-leg grid-tied inverter for V2G application, which can simplify the third-order of the system to be an equivalent first-order system. 2) the current control performance of the V2G system can be improved significantly in terms of easy implementation, high accuracy, low THD and good robustness. Simulations and experiments on a test rig of $10 \mathrm{~kW}$ grid-tied inverter are executed to prove the highperformance of proposed strategy.

The remaining parts of the paper are arranged as follows: a mathematical model of V2G three-phase four-leg inverter with LCL filter is established in Section II. The analysis and synthesis of the current control strategy is shown in Section III. Section IV gives simulation and experiment results of the proposed strategy. Section V provides the conclusion.

\section{MODEL OF THE INVERTER}

The topology of the grid-connected three-phase four-leg inverter with LCL filter is shown in Fig.2. The four legs ( $a, b$, $\mathrm{c}, \mathrm{n}$ ) comprise of 8 IGBTs (Insulated Gate Bipolar Transistor) power electronic switches named as $\mathrm{Q}_{1} \sim \mathrm{Q}_{8}$ in the topology. $v_{\mathrm{ga}}, v_{\mathrm{gb}}$ and $v_{\mathrm{gc}}$ are grid voltages of three-phase, respectively. DC bus voltage is denoted as $V_{\mathrm{dc}} . i_{1 j}, i_{2 j}(j=\mathrm{a}, \mathrm{b}, \mathrm{c})$ are currents of the two inductances of corresponding phase, respectively. The voltages between point a, b, c, n, and the DC ground are denoted as $v_{\mathrm{a}}, v_{\mathrm{b}}, v_{\mathrm{c}}, v_{\mathrm{n}}$, respectively. The capacitor voltages of the three phases LCL filter are denoted as $v_{\mathrm{ca}}, v_{\mathrm{cb}}, v_{\mathrm{cc}}$, respectively.

The proposed scheme comprises of a WAIC based DB controller and a paralleled plug-in RC for three-phase fourleg inverter. A 3D-SVM is used to convert the control outputs of the proposed controller into PWM signals for driving the IGBTs[23]

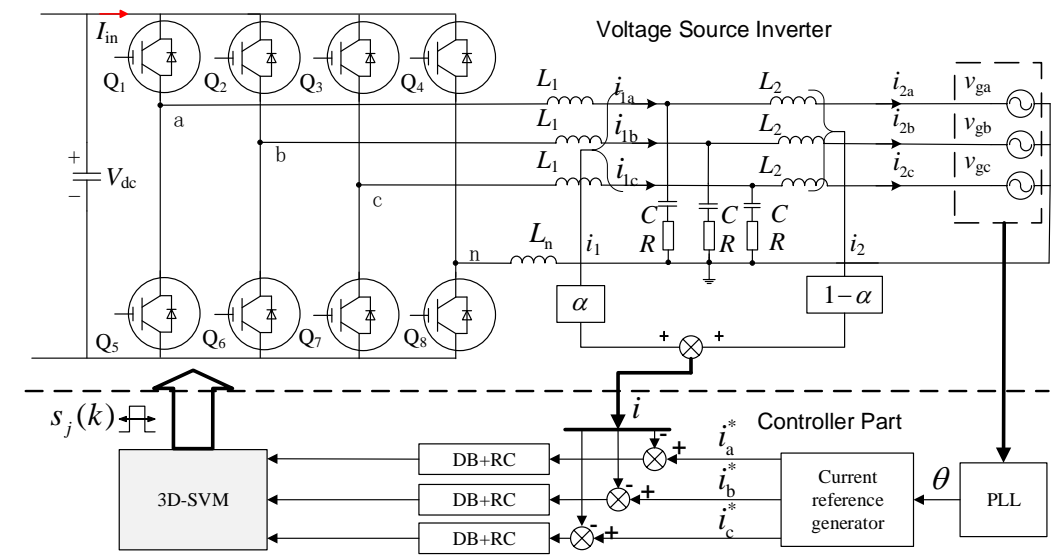

Fig. 2 Topology of four-leg VSI for V2G interface

\section{A. Modelling of the Inverter}

The mathematical model of the three-phase four-leg inverter shown in Fig. 2 can be obtained as

$$
\left\{\begin{array}{l}
L_{1}\left[\begin{array}{l}
\dot{i}_{1 \mathrm{a}} \\
\dot{i}_{1 \mathrm{~b}} \\
\dot{i}_{1 \mathrm{c}}
\end{array}\right]+R C\left[\begin{array}{l}
\dot{v}_{\mathrm{ca}} \\
\dot{v}_{\mathrm{cb}} \\
\dot{v}_{\mathrm{cc}}
\end{array}\right]=\left[\begin{array}{l}
v_{a} \\
v_{b} \\
v_{c}
\end{array}\right]-\left[\begin{array}{l}
v_{c a} \\
v_{c b} \\
v_{c c}
\end{array}\right] \\
C\left[\begin{array}{l}
\dot{v}_{\mathrm{ca}} \\
\dot{v}_{\mathrm{cb}} \\
\dot{v}_{\mathrm{cc}}
\end{array}\right]=\left[\begin{array}{l}
i_{1 a} \\
i_{1 b} \\
i_{1 c}
\end{array}\right]-\left[\begin{array}{l}
i_{2 a} \\
i_{2 b} \\
i_{2 c}
\end{array}\right] \\
R C\left[\begin{array}{l}
\dot{v}_{\mathrm{ca}} \\
\dot{v}_{\mathrm{cb}} \\
\dot{v}_{\mathrm{cc}}
\end{array}\right]-L_{2}\left[\begin{array}{l}
\dot{i}_{2 \mathrm{a}} \\
\dot{i}_{2 \mathrm{~b}} \\
\dot{i}_{2 \mathrm{c}}
\end{array}\right]=\left[\begin{array}{l}
v_{g a} \\
v_{g b} \\
v_{g c}
\end{array}\right]-\left[\begin{array}{l}
v_{c a} \\
v_{c b} \\
v_{c c}
\end{array}\right]
\end{array}\right.
$$

Eq. (1) indicates that the three-phase four-leg inverter is decoupled into three separated single-phase inverter circuits [24].

\section{B. Weighted Average Inductor Current Scheme}

As shown in Fig. 3, the WAIC scheme is developed for each phase LCL filter to simplify the synthesis of the current controller, where $V_{\mathrm{g} j}(s)$ and $V_{i}(s)$ are voltages of grid-side and inverter output side, respectively, the resistor $\mathrm{R}$ is used to damp the resonance, and the capacitor $\mathrm{C}$ is used to remove high frequency current.

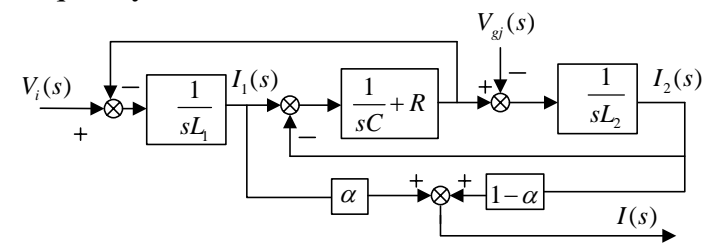

Fig. 3. Block diagram of each phase WAIC scheme.

The transfer functions from the inductor currents of the LCL filter to the inverter output voltage can be derived as

$$
\left\{\begin{array}{l}
\frac{I_{1}(s)}{V_{i}(s)}=\frac{Z_{2}+Z_{c}}{Z_{1} Z_{2}+Z_{1} Z_{c}+Z_{2} Z_{c}} \\
\frac{I_{2}(s)}{V_{i}(s)}=\frac{Z_{c}}{Z_{1} Z_{2}+Z_{1} Z_{c}+Z_{2} Z_{c}}
\end{array}\right.
$$


where

$$
\left\{\begin{array}{l}
Z_{1}=s L_{1} \\
Z_{2}=s L_{2} \\
Z_{c}=1 / s C+R
\end{array}\right.
$$

Define $L=L_{1}+L_{2}$ and the weighting factor $\alpha=L_{1} / L$, Eq. (2) can be rewritten into two $3^{\text {rd }}$ order transfer functions as below

$$
\left\{\begin{array}{l}
\frac{I_{1}(s)}{V_{i}(s)}=\frac{(1-\alpha) L C s^{2}+R C s+1}{\alpha(1-\alpha) L^{2} C s^{3}+R C L s^{2}+s L} \\
\frac{I_{2}(s)}{V_{i}(s)}=\frac{R C s+1}{\alpha(1-\alpha) L^{2} C s^{3}+R C L s^{2}+s L}
\end{array}\right.
$$

Let us define a weighted average inductor current as

$$
I(s)=\alpha I_{1}(s)+(1-\alpha) I_{2}(s)
$$

Substitute Eq. (4) into (5), we can get a first-order control plant $G_{\mathrm{p}}(s)$ as below

$$
G_{\mathrm{p}}(s)=\frac{I(s)}{V_{i}(s)}=\frac{1}{s L}
$$

Therefore, the third-order system would be simplified to be an equivalent first-order L filter by using the WAIC scheme.

\section{Proposed CURRENT CONTROL STRATEGY}

This paper develops a high-performance current control scheme for the grid-tied three-phase four-leg inverter. It comprises of a simple WAIC based DB and a paralleled plugin $\mathrm{RC}$ as shown in Fig.4.

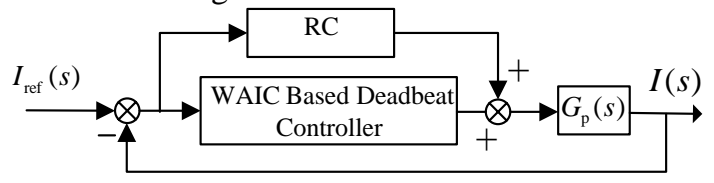

Fig. 4. Block diagram of the strategy

\section{A. WAIC Based Deadbeat Control}

The WAIC based $1^{\text {st }}$-order $L$ filter is described as

$$
v_{j}=L \frac{d i_{j}}{d t}+v_{\mathrm{g} j}
$$

where $v_{j}$ and $v_{\mathrm{g} j}$ is the voltage of invert output side and grid side, respectively. $i_{j}$ is the weighted average inductor current of the LCL filter, with $j=a, b, c$ indicates the phase.

In discrete time domain with the sampling interval $T_{\mathrm{s}}$, equation (7) could be

$$
i_{j}(k+1)=i_{j}(k)+\frac{T_{\mathrm{s}}\left[v_{j}(k)-v_{\mathrm{g} j}(k)\right]}{L}
$$

If the current is tracked in one period, namely $i_{j}(k+1)=i_{j}^{*}(k)$, where $i_{j}^{*}(k)$ is reference current, DB current control is obtained as the Eq.(9) by replacing $i_{j}(k+1)$ with $i_{j}^{*}(k)$ in Eq. (8)

$$
v_{j}(k)=\frac{L}{T_{\mathrm{s}}}\left[i_{j}^{*}(k)-i_{j}(k)\right]+v_{\mathrm{g} j}(k)
$$

According to Eq. (9), we can draw out the block diagram as shown in Fig. 5

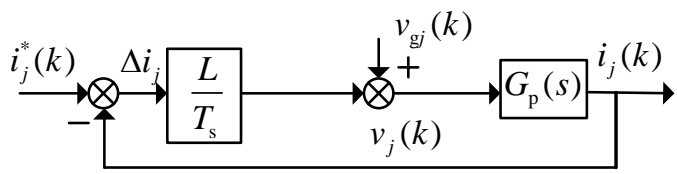

Fig. 5. Block diagram of DB controlled current loop.

DB control can force the output to track the reference with one sampling step delay, which means that DB can provide fast dynamic response [10]. However, DB control is sensitive to system uncertainties in practice, especially unmodeled time delay, e.g. computation delay, system control delay, etc. The unmodelled time delay not only will degrade the performance of the DB control system [25, 26], but also have significant impact on the system stability.

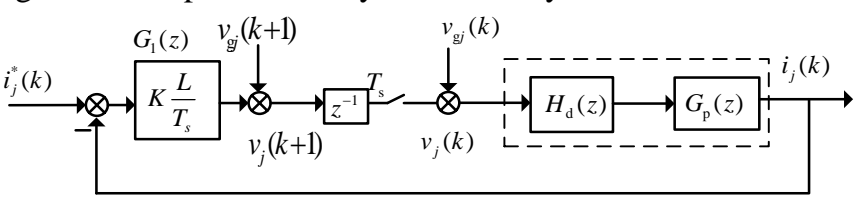

Fig. 6. Block diagram of DB control with system time delays.

The block diagram of DB controlled inverter with system time delays is shown in Fig. 6, where the computation delay is represented as one sampling time delay $\mathrm{z}^{-1}$, and other unmodelled time delay is given as $H_{\mathrm{d}}(s)=e^{-s T_{\mathrm{d}}}$ with $T_{\mathrm{d}}$ being the time length of unmodelled delay $[25,20] . H_{\mathrm{d}}(\mathrm{z})$ shown in Fig. 6 is the discretization of $H_{\mathrm{d}}(\mathrm{s})$. The coefficient $K$ is used to replace unit coefficient of the inductance $L . G_{\mathrm{p}}(\mathrm{z})$ is the discretization of $G_{\mathrm{p}}(\mathrm{s})$ using zero-order holder $(\mathrm{ZOH})$ $G_{\mathrm{h}}(s)=\left(1-e^{s T_{\mathrm{s}}}\right) / s$ :

$$
G_{\mathrm{p}}(z)=\mathcal{Z}\left[G_{\mathrm{h}}(s) \cdot G_{\mathrm{p}}(s)\right]=\frac{T_{\mathrm{s}}}{L} \cdot \frac{1}{z-1}
$$

Using the first order Taylor expansion, the delay function $H_{\mathrm{d}}(s)=e^{-s T_{\mathrm{d}}}$ can be written as:

$$
e^{-s T_{\mathrm{d}}}=1-s T_{\mathrm{d}}+\frac{\left(-s T_{\mathrm{d}}\right) 2}{2 !}+\cdots \approx 1-s T_{\mathrm{d}}
$$

If the delay time $T_{\mathrm{d}}$ is approximately treated as $T_{d} \approx m \cdot T_{s}$ , where $m$ is integer times of the sampling period $T_{\mathrm{s}}$. Using the Tustin transfer, the delay function of $H_{\mathrm{d}}(s)$ could be discretized as:

$$
H_{\mathrm{d}}(z)=1-2 m \cdot \frac{z-1}{z+1}
$$

Hence the open-loop transfer function of Fig.6 can be expressed as

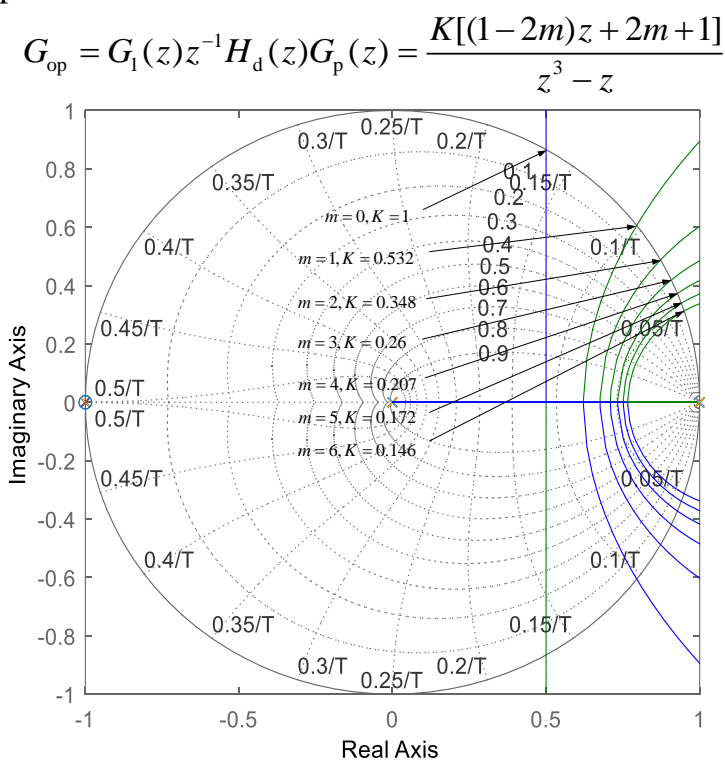

Fig. 7. Root locus of DB controller with delays in z-plane 
The root locus shown in Fig.7 presents the influence of time delay steps $(m=0 \sim 6)$ on DB controller in z-plane. To ensure the stability of control system, the value of $K$ should be within a certain limit range to ensure the root locus inside the unit circle. When $T_{d}=m T_{s}$ is increased from 0 to $6 T_{s}$, the stability range of $K$ is decreased from $K \in(0,1)$ to $K \in(0$, 0.146). It indicates that the unmodelled delay may significantly degrade the stability of the DB control system. Fig. 7 indicates that the increase of delay time $T_{\mathrm{d}}$ will decrease stability range of $K$. In other words, the DB controller is not immune to these unmodelled system delays [20].

Furthermore, the DB controllers highly depend on the accurate system model. But we can hardly get accurate models of grid-connected inverters with various disturbances and uncertainties in practice. The DB controller cannot eliminate periodic current harmonics distortions. To ensure exact current tracking and harmonic attenuation, an IMP based RC is plugged to reinforce the DB controller.

\section{B. Plug-in Repetitive Controller}

In practice, since the WAIC based DB controller cannot eliminate periodic current harmonics distortion [27]. In order to remove the residual harmonic distortion from the feed-in current [21], a plug-in phase-lead compensation RC shows in Eq. (14) is added to reinforce the WAIC based DB controller.

$$
G_{\mathrm{rc}}(z)=k_{r c} \frac{z^{-N+p} Q(z)}{1-z^{-N} Q(z)}
$$

where $N=f_{\mathrm{s}} / f_{0}$ with $f_{\mathrm{s}}$ and $f_{0}$ being the sampling frequency and grid frequency, the low-pass filter $Q(z)=a_{0} z+a_{1}+a_{0} z^{-1}$ with $2 a_{0}+a_{1}=1$ and $|Q(z)| \leq 1$ is usually used to achieve a trade-off between the system robustness and tracking accuracy. The $k_{r c}$ is the control gain for tuning the convergence rate of $\mathrm{RC}$, and $z^{p}$ provides linear phase lead compensation. The implementation of the RC in Eq. (14) is shown in Fig. 8, and $p=3, a_{0}=0.25, a_{1}=0.5$ are employed in the following simulations and experiments.

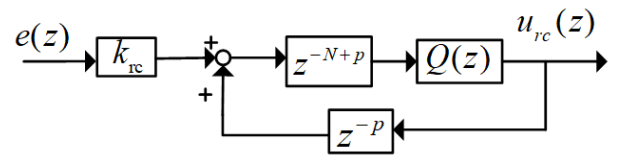

Fig. 8. The general RC with phase-lead compensation

\section{Closed-loop Current Loop Stability Analysis}

When the WAIC based DB controller plus the plug-in RC is applied to the three-phase four-leg inverter controller system, the transfer function of the closed-loop current control without considering delay can be written as:

$$
\begin{aligned}
\phi(z) & =\frac{I_{j}(z)}{I_{j}^{*}(z)}=\frac{\left[G_{1}(z)+G_{\mathrm{rc}}(z)\right] G_{\mathrm{p}}(z)}{1+\left[G_{1}(z)+G_{\mathrm{rc}}(z)\right] G_{\mathrm{p}}(z)} \\
& =1-\frac{\left(1-z^{-N} Q(z)\right) \cdot\left[1+G_{1}(z) G_{\mathrm{p}}(z)\right]^{-1}}{1-\left[1-k_{\mathrm{rc}} z^{p} G_{\mathrm{s}}(z)\right] \cdot z^{-N} Q(z)}
\end{aligned}
$$

where $G_{\mathrm{s}}(z)=\frac{G_{\mathrm{p}}(z)}{1+G_{1}(z) G_{\mathrm{p}}(z)}$

The following conditions should be held to ensure the above system to be stable:

1) The DB control system without the RC is inherently stable, that is to say, the poles of $G_{s}(z)$ should locate in the unit circle.
2) All the roots of $1-\left[1-k_{\mathrm{rc}} z^{p} G_{\mathrm{s}}(z)\right] z^{-N} Q(z)=0$ should locate in the unit circle, i.e.

$$
\left|1-k_{\mathrm{rc}} z^{p} G_{\mathrm{s}}(z)\right|<1 /|Q(z)|
$$

where $z=e^{j \omega T_{\mathrm{s}}}$, with $\omega<\pi / T_{\mathrm{s}}$.

Eq. (16) clearly indicates that $Q(z)$ with $|Q(z)| \leq 1$ will reinforce the system stability.

\section{SimUlation AND EXPERIMENTAL VERIFICATION}

A test rig of $10 \mathrm{~kW}$ grid-tied three-phase four-leg inverter has been configured to validate the proposed control strategy via simulations and experiments. TABLE I. list out the inverter parameters.

TABLE I. INVERTER PARAMETERS

\begin{tabular}{lll}
\hline \hline Parameters & Value & Unit \\
\hline DC-link voltage $V_{\mathrm{dc}}$ & 700 & $\mathrm{~V}$ \\
Inductor $L_{1}$ & 3 & $\mathrm{mH}$ \\
Inductor $L_{2}$ & 1 & $\mathrm{mH}$ \\
Capacitor filter $C$ & 5 & $\mathrm{uF}$ \\
Damping resistance $R$ & 24 & $\Omega$ \\
Sampling frequency & 20 & $\mathrm{kHz}$ \\
Grid frequency & 50 & $\mathrm{~Hz}$ \\
Rated RMS voltage & 220 & $\mathrm{~V}$ \\
Rated currents & 15 & $\mathrm{~A}$ \\
Rated power & 10 & $\mathrm{kVA}$ \\
\hline \hline
\end{tabular}

\section{A. Simulation Results}

The output currents of $i_{1}, i_{2}$ and the feed-in grid current output error percentage at rated power are shown in Fig.9.
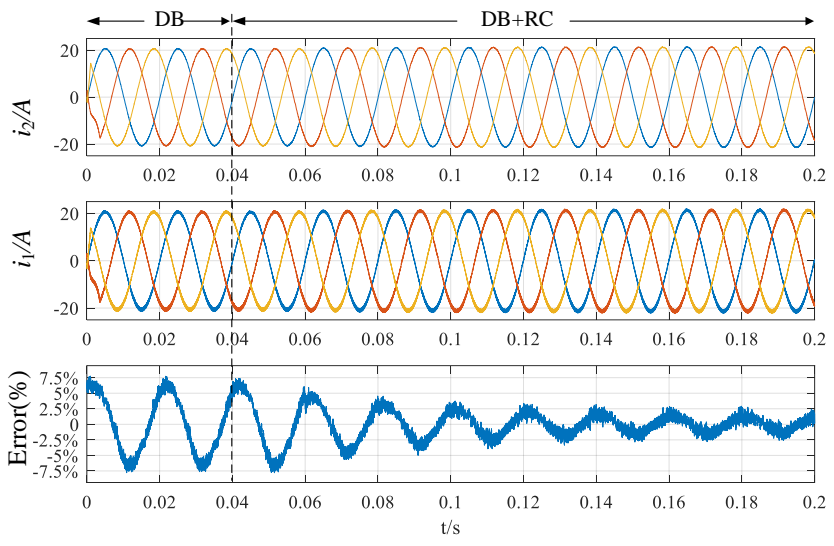

Fig.9. Plug-in RC is added onto the WAIC based DB controlled inverter at the time $\mathrm{t}=0.04 \mathrm{~s}$.

It can be seen from Fig. 9 that, the peak of current control error under the WAIC based DB control strategy is about $\pm 7.5 \%$ of the reference peak current of $21.2 \mathrm{~A}$ before the $\mathrm{RC}$ is plugged in at the time $t=0.04 \mathrm{~s}$; and the peak of current control error is reduced from $\pm 7.5 \%$ to about $\pm 2.5 \%$ within $0.1 \mathrm{~s}$ after the $\mathrm{RC}$ is plugged in at the time $t=0.04 \mathrm{~s}$. Simulation results show that the proposed DB with plug-in RC current control scheme is of fast response and high control accuracy.

Dynamic responses of feed-in current with proposed current control scheme are shown in Fig. 10. It shows that feed-in currents can rapidly track their references within $1 \mathrm{~ms}$ under step changes of references between 15A and 10A. 
Simulation results indicate that the proposed DB plus plug-in $\mathrm{RC}$ is of fast response and robust to sudden reference changes.

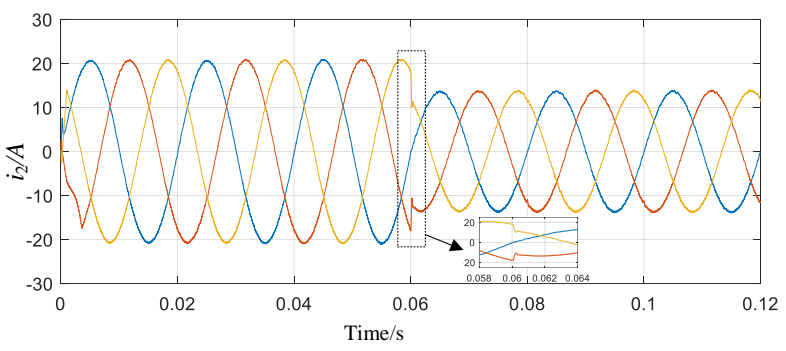

(a)

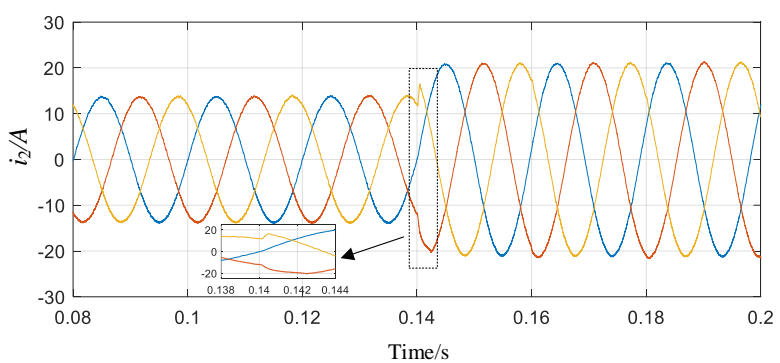

(b)

Fig. 10. Dynamic responses of feed-in grid current with the proposed strategy. (a) reference current steps from $15 \mathrm{~A}$ to $10 \mathrm{~A}$ (b)reference current steps from $10 \mathrm{~A}$ to $15 \mathrm{~A}$

\section{B. Experiment Results}

Figure 11 shows the experiment platform of a 10kW DSP controlled three-phase four-leg grid-connected inverter for V2G application interface. Note that, as one system disturbance, the THD of the grid voltage is $2.96 \%$ in the following experiments.

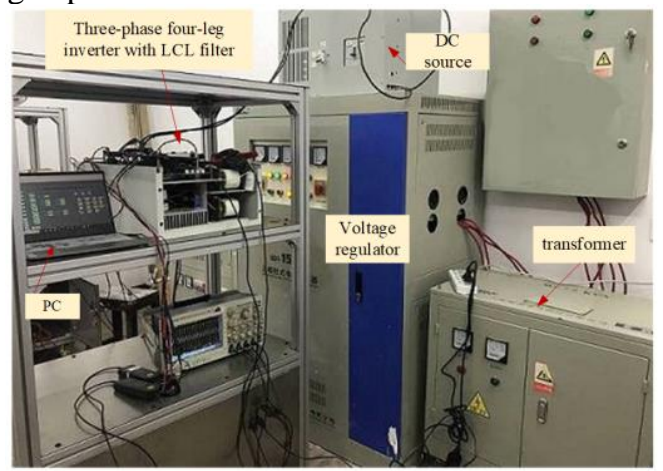

Fig. 11. The test rig of $10 \mathrm{~kW}$ four-leg Inverter.

The steady-state feed-in grid currents at rated power and their harmonic spectrum with WAIC based DB current control strategy is shown in Fig. 12. We can see that the THD of the feed-in currents is up to $7.82 \%$, which is not satisfied the standard of $5 \%$ specified in IEEE std. 1547. The experiment results show that WAIC based DB current control cannot well eliminate periodic current harmonic distortions in practice.

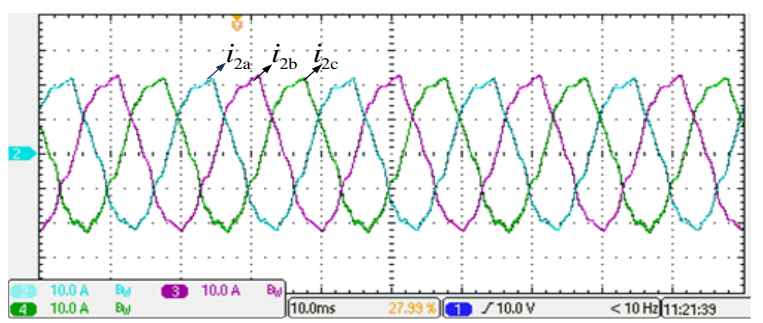

(a)

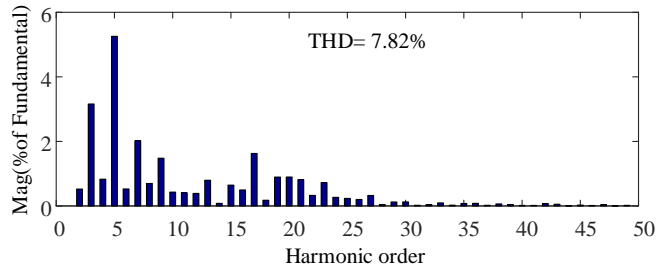

(b)

Fig. 12. Current responses with WAIC based DB controller at rated power. (a) feed-in grid currents (b) harmonic spectrum

To remove harmonic distortion from the feed-in current, a plug-in RC is added to reinforce the DB controller. Fig. 13 shows the output current at rated reference current of $15 \mathrm{~A}$ RMS with the proposed control strategy. We can see that the THD of fed-in current is decreased remarkably to $2.06 \%$, with the feed-in current and grid voltage in the same phase. The output current tracking error is only about $\pm 0.2 \mathrm{~A}$ in the presence of the THD $=2.96 \%$ of the grid voltages. Experiment results show that the proposed DB plus plug-in RC could achieve accurate current tracking and eliminate the harmonics distortion even under the condition of grid voltage distortions.

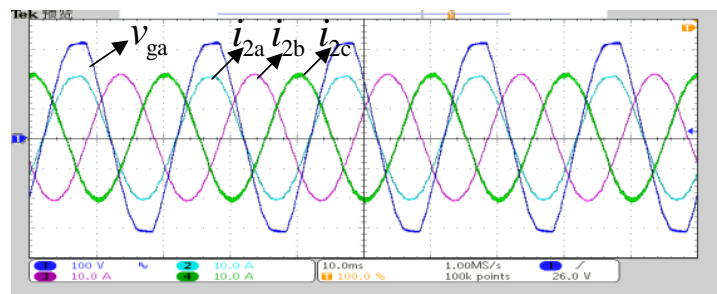

(a)

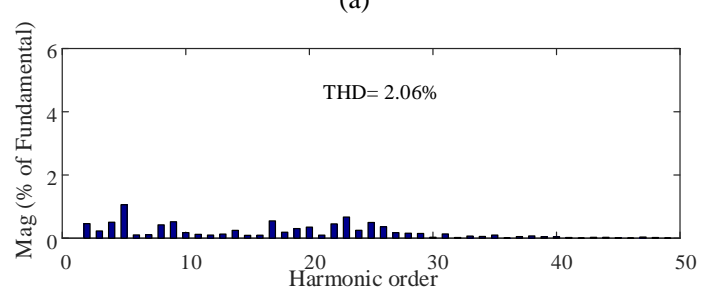

(b)

Fig. 13. Current output with proposed DB plus plug-in RC at rated power. (a) feed-in grid current (b) harmonic spectrum

Fig. 14 shows the dynamic feed-in current responses under step reference changes between 15A and 10A. The feed-in currents can track their reference rapidly within $4 \mathrm{~ms}$ when references change. Experiment results show that the proposed DB plus plug-in RC strategy is of fast response and robust to sudden reference changes.

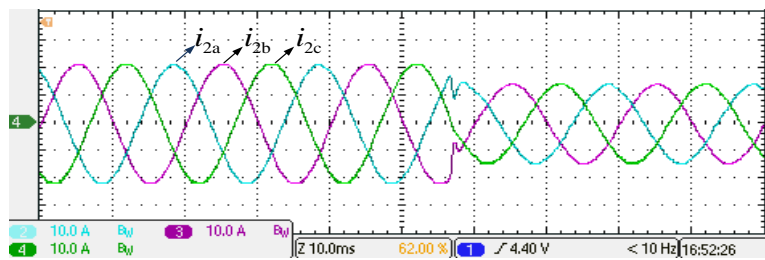

(a)

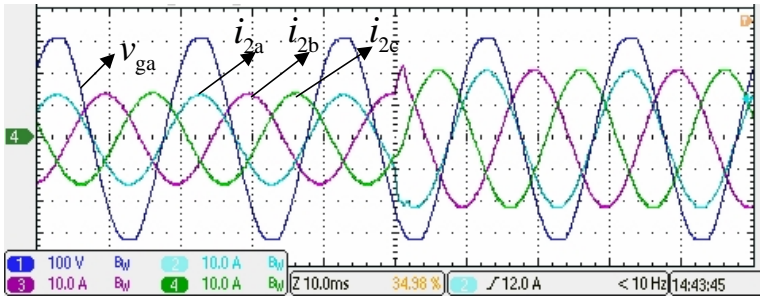

(b)

Fig. 14. Dynamic responses of the feed-in grid currents with proposed DB plus plug-in RC. (a) from $15 \mathrm{~A}$ to $10 \mathrm{~A}$. (b) from $10 \mathrm{~A}$ to $15 \mathrm{~A}$ 


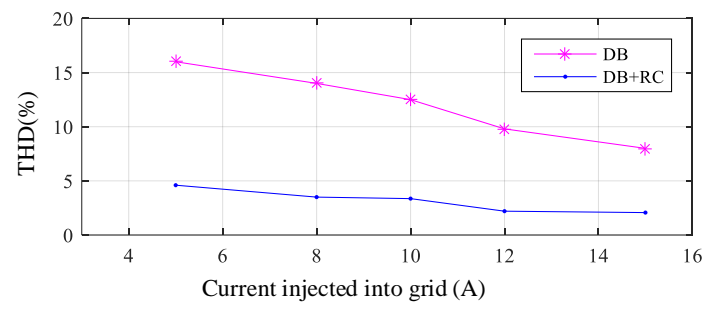

Fig. 15. THD of feed-in currents

The IEEE std. 1547 has specified the maximum THD of feed-in current should not exceed $5 \%$ at rated current capacity. Fig. 15 shows that the THD of feed-in currents with the proposed scheme is always below the threshold of $5 \%$ in the range of $5 \mathrm{~A}$ to $15 \mathrm{~A}$, while the THD of feed-in currents with WAIC based DB controller is always above $5 \%$. That is to say, the $\mathrm{V} 2 \mathrm{G}$ inverter with proposed DB plus plug-in RC can offer good quality feed-in current in the range of $30 \%$ to $100 \%$ of rated power.

All the experiment results show that the proposed current control strategy provides a simple high-performance solution to the three-phase four-leg V2G inverters with LCL filter.

\section{CONCLUSION}

This paper proposed a simple high performance current control scheme for V2G three-phase four-leg inverters with LCL filter, which comprises of a WAIC-based deadbeat (DB) controller and a plug-in repetitive controller (RC). Using the WAIC, the third-order LCL filter can be simplified to be an equivalent $1^{\text {st }}$ order L filter, which subsequently simplify the design and analysis of the current control scheme. Based on the equivalent $1^{\text {st }}$ order $\mathrm{L}$ filter, a simple $\mathrm{DB}$ controller is developed for the three-phase four-leg inverter. The DB controller is of very fast response and easy implementation, but is not immune to system time delay and various uncertainties. The stability analysis of the DB controlled inverter is conducted to investigate the impact of the unmodelled system time delay. To overcome the disadvantages of the DB controller, a plug-in RC is added to reinforce the $\mathrm{DB}$ controller to remove harmonic distortion from the feed-in current. The results of both simulations and experiments on a $10 \mathrm{~kW}$ grid-connected three-phase four-leg inverter with LCL filter show that the proposed current control scheme offers a very simple high performance control solution to $\mathrm{V} 2 \mathrm{G}$ interface inverters, which is of high accuracy, fast response and good robustness and easy implementation in the presence of various uncertainties.

\section{REFERENCES}

[1] S. Faddel, T. Youssef, A. T. Elsayed, and O. A. Mohammed, "An Automated Charger for Large-Scale Adoption of Electric Vehicles," IEEE Transactions on Transportation Electrification, vol. 4, no. 4, pp. 971 984, Dec. 2018.

[2] J. Traube et al., "Mitigation of Solar Irradiance Intermittency in Photovoltaic Power Systems With Integrated Electric-Vehicle Charging Functionality," IEEE Transactions on Power Electronics, vol. 28, no. 6, pp. 3058-3067, Jun. 2013.

[3] H. Yin, W. Zhou, M. Li, C. Ma, and C. Zhao, "An Adaptive Fuzzy Logic-Based Energy Management Strategy on Battery/Ultracapacitor Hybrid Electric Vehicles," IEEE Transactions on Transportation Electrification, vol. 2, no. 3, pp. 300-311, Sep. 2016.

[4] H. Zhang, Z. Hu, Z. Xu, and Y. Song, "Evaluation of Achievable Vehicle-to-Grid Capacity Using Aggregate PEV Model," IEEE Transactions on Power Systems, vol. 32, no. 1, pp. 784-794, Jan. 2017.

[5] A. Sharma and S. Sharma, "Review of power electronics in vehicle-togrid systems," Journal of Energy Storage, vol. 21, pp. 337-361, Feb. 2019.
[6] M. Yilmaz and P. T. Krein, "Review of the Impact of Vehicle-to-Grid Technologies on Distribution Systems and Utility Interfaces," IEEE Transactions on Power Electronics, vol. 28, no. 12, pp. 5673-5689, Dec. 2013.

[7] Q. Chen, X. Luo, L. Zhang, and S. Quan, "Model Predictive Control for Three-Phase Four-Leg Grid-Tied Inverters," IEEE Access, vol. 5, pp. 2834-2841, Mar. 2017.

[8] V.-T. Doan, K.-Y. Kim, W. Choi, and D.-W. Kim, "Design of a Hybrid Controller for the Three-phase Four-leg Voltage-source Inverter with Unbalanced Load," Journal of Power Electronics, vol. 17, no. 1, pp. 181-189, Jan. 2017.

[9] M. Rivera, V. Yaramasu, A. Llor, J. Rodriguez, B. Wu, and M. Fadel, "Digital Predictive Current Control of a Three-Phase Four-Leg Inverter," IEEE Transactions on Industrial Electronics, vol. 60, no. 11, pp. 4903-4912, Nov. 2013.

[10] Y. Xing, C. Tan, Q. Chen, L. Zhang, K. Zhou, "An Improved Deadbeat plus Plug-in Repetitive Controller for Three-phase Four-leg Inverters," IECON 2017 - 43rd Annual Conference of the IEEE Industrial Electronics Society. pp.6325-6329.Nov.2017

[11] Y. Tang, P. C. Loh, P. Wang, F. H. Choo, F. Gao, and F. Blaabjerg, "Generalized design of high performance shunt active power filter with output LCL filter," IEEE Transactions on Industrial Electronics, vol. 59, no. 3, pp. 1443-1452, Mar. 2012.

[12] D. Pan, X. Ruan, C. Bao, W. Li, and X. Wang, "Capacitor-CurrentFeedback Active Damping With Reduced Computation Delay for Improving Robustness of LCL-Type Grid-Connected Inverter," IEEE Transactions on Power Electronics, vol. 29, no. 7, pp. 3414-3427, July. 2014.

[13] A. Timbus, M. Liserre, R. Teodorescu, P. Rodriguez, and F. Blaabjerg, "Evaluation of Current Controllers for Distributed Power Generation Systems," IEEE Transactions on Power Electronics, vol. 24, no. 3, pp. 654-664, Mar. 2009.

[14] E. Wu and P. W. Lehn, "Digital Current Control of a Voltage Source Converter With Active Damping of LCL Resonance," IEEE Transactions on Power Electronics, vol. 21, no. 5, pp. 1364-1373, Sep. 2006.

[15] G. Shen, X. Zhu, J. Zhang, and D. Xu, "A New Feedback Method for PR Current Control of LCL-Filter-Based Grid-Connected Inverter," IEEE Transactions on Industrial Electronics, vol. 57, no. 6, pp. 2033 2041, Jun. 2010

[16] G. Shen, D. Xu, L. Cao, and X. Zhu, "An Improved Control Strategy for Grid-Connected Voltage Source Inverters with an LCL Filter," IEEE Transactions on Power Electronics, vol. 23, no. 4, pp. 1899-1906, Jul. 2008.

[17] Y. Han, Z. Li, P. Yang, C. Wang, L. Xu, and J. M. Guerrero, "Analysis and Design of Improved Weighted Average Current Control Strategy for LCL-Type Grid-Connected Inverters," IEEE Transactions on Energy Conversion, vol. 32, no. 3, pp. 941-952, Sep. 2017

[18] J. He, Y. W. Li, D. Xu, X. Liang, B. Liang, and C. Wang, "Deadbeat Weighted Average Current Control With Corrective Feed-Forward Compensation for Microgrid Converters With Nonstandard LCL Filter," IEEE Transactions on Power Electronics, vol. 32, no. 4, pp. 2661 2674, Apr. 2017

[19] D. Pan, X. Ruan, X. Wang, B. Frede, W. Xuehua, and Q. Zhou, "A Highly Robust Single-Loop Current Control Scheme for Grid-Connected Inverter With an Improved LCCL Filter Configuration," IEEE Transactions on Power Electronics, vol. 33, no. 10, pp. 8474-8487, Oct. 2018.

[20] J. Gao, X. Huang, F. Lin, Q. Zheng, "Deadbeat Control Strategy for PWM Rectifiers Based on Repetitive Observer,". Transactions of China Electrotechnical Society, vol. 25, no. 06, pp. 47-54, Jun. 2010.

[21] K. Zhou, D. Wang, Y. Yang, and F. Blaabjerg, Periodic Control of Power Electronic Converters [M]. London, United Kingdom: CPI Group(UK), 2017:59-70.

[22] K. Zhou, Z. Qiu, N. R. Watson, and Y. Liu, "Mechanism and elimination of harmonic current injection from single-phase grid-connected PWM converters," IET Power Electronics, vol. 6, no. 1, pp. 88-95, Nov. 2013.

[23] E. Esmaeil, F. Shahrokh, I.-E. Hossein, and B. Frede, "Modulation technique for Four-Leg Voltage Source Inverter without a Look-Up Table," IET Power Electronics, vol. 9, no. 4, pp. 648-656, Mar. 2016.

[24] J. Wang, Q. Chen, L. Liu, L. Zhang, and S. Quan, "Grid-connected Control for Inverters Oriented to Microgrid with Unbalance Compensation for Three-phase Voltage," Automation of Electric Power Systems, vol. 41, no. 8, pp. 38-44, Apr. 2017.

[25] D. Pan, X. Ruan, C. Bao, W. Li, and X. Wang, "Optimized Controller Design for LCL-Type Grid-Connected Inverter to Achieve High Robustness Against Grid-Impedance Variation," IEEE Transactions on Industrial Electronics, vol. 62, no. 3, pp. 1537-1547, Mar. 2015.

[26] L. Yang, S. Yang, W. Zhang, Z. Chen, and L. Xu, "The Improved Deadbeat Predictive Current Control Method for Single-phase PWM 
Rectifiers," Proceedings of the CSEE, vol.35, no. 22, pp. 5842-5850, Nov. 2015

[27] N. He et al., "weighted average current control in a three-phase grid inverter with an LCL filter," IEEE Transactions on Power Electronics, vol. 28, no. 6, pp. 2785-2797, Jun. 2013.

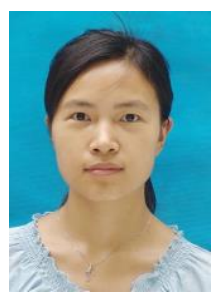

Cuilan Tan received the B.S. and M.S. degree in School of Automation, Wuhan University of

Technology, Wuhan, China, in 2002 and 2009 respectively, where she is currently pursuing the $\mathrm{Ph} . \mathrm{D}$. degree. Since 2009, she has been a faculty member at Jianghan University, Wuhan, China, her research interests include power electronics and electric drives, current control for grid-tied inverters

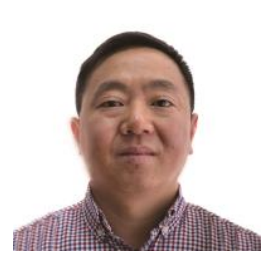

Qihong Chen (M'08) received the Ph.D. degree in control science and engineering from Southeast University, Nanjing, China, in 2003.He is currently a Professor with the Wuhan University of Technology, Wuhan, China. His current research interests include grid tied inverters and predictive control.

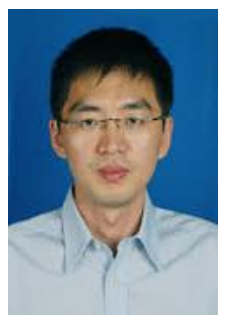

Keliang Zhou (M'04-SM'08) received the B.Sc. degree from the Huazhong University of Science and Technology, Wuhan, China, the M.Eng. degree from Wuhan Transportation University (now the Wuhan University of Technology), Wuhan, and the Ph.D. degree in Electrical Engineering from Nanyang Technological University, Singapore, in 1992, 1995, and 2002, respectively. $\mathrm{He}$ is currently a Senior Lecturer with James Watt School of Engineering at the University of Glasgow, Glasgow in U.K. since 2014 $\mathrm{He}$ has authored or co-authored one monograph on "Periodic Control of Power Electronic Converters", more than 100 technical papers and several granted patents in relevant areas. His teaching and research interests include power electronics and electric drives, renewable sources assessment and integration, general PID control and applications.

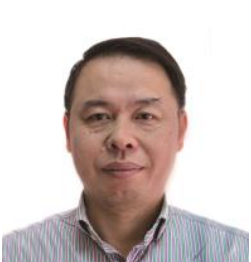

Liyan Zhang received the $\mathrm{Ph} . \mathrm{D}$. degree in control science and engineering from Zhejiang University, Hangzhou, China, in 2004. He is currently a Professor with the Wuhan University of Technology, Wuhan, China. His current research interests include predictive control, and modeling and control of hybrid electric vehicles. 